\section{Assessment of adverse drug reactions in the home manage- ment of malaria cases of children under 5 years using artemisinin-based combination therapy in Mfou health district, Center region of Cameroon}

\author{
Louis Essengue Bahina, ${ }^{1}$ \\ Christian Jean Youmba, ${ }^{2}$ \\ Rodrigue Biguioh Mabvouna, ${ }^{3}$ \\ Joëlle Sobngwi ${ }^{1}$
}

${ }^{1}$ Catholic University of Central Africa, Yaoundé, Cameroon; ${ }^{2}$ Cameroonian Association for Social Marketing (ACMS), Yaoundé, Cameroon; ${ }^{3}$ Faculty of Medicine and Surgery, University of Roma "Tor Vergata", Rome, Italy

\section{Abstract \\ Malaria remains one of the major public} health concerns in Cameroon. Its treatment is frequently initiated at home, most often with street drugs. The home management of malaria cases entails the prescription of Artemisinin-based combination (ACTs) as first-line therapy for treatment of uncomplicated malaria after having confirmed the malaria case using rapid diagnostic tests. But induced adverse reactions of this therapy are not well known in Cameroon. Thus, a prospective, observational, cohort study of adverse events associated with ACTs was conducted from January 2013 to November 2013 in the health district of Mfou. Children under 5 years receiving ACTs for malaria treatment at home were enrolled. Suspected ADRs and other clinical events were recorded. Data were managed and analysed using Epi Info version 3.5.3 and Statistical Package for Social Sciences, statistical software version 20. Of the 479 children investigated, $56.8 \%$ $(\mathrm{n}=272 / 479)$ were males, the age group 25-59 months $(49.5 \%$; $n=237 / 479)$ was most represented, 27.1\% $(n=130 / 479)$ had experienced one form of ADRs, male children $(56.2 \%$; $\mathrm{n}=73 / 130)$ and the age group 25-59 months $(50.8 \% ; n=66 / 130)$ were most affected. No significant association was found between age, sex and incidence of adverse ACTs reactions. The main experienced ACTs reactions were tiredness $(43.1 \% ; n=56 / 130)$ followed by lack of appetite $(24.6 \% ; n=32 / 130)$. The incidence ACTs ARDs was found to be relatively low and tolerable. Home management of malaria cases using ACTs should be encouraged and community members should be trained to improve the recognizing and reporting of adverse effects.

\section{Introduction}

In the past, only health professionals managed medicines. But nowadays, the community through community health workers is also involved in the management and handling of drugs. ${ }^{1}$ This type of partnership in found in areas of malaria intense transmission, where antimalarial drugs are prescribed for the treatment of malaria and suspected cases (fevers). ${ }^{2-5}$ Community health workers are community members trained to treat malaria at home after having confirmed the malaria cases using rapid diagnostic tests. They are also involved in the distribution of antimalarial for presumptive treatment of fever in children under five years. ${ }^{2-5}$

In response to the resistance observed in previously antimalarial drugs, the World Health Organization (WHO) recommend to use Artemisinin-based combination therapy (ACTs) as first-line therapy for the treatment of uncomplicated Plasmodium falciparum malaria. ${ }^{6-8}$ Two types of ACT have been adopted in Cameroon: Artesunate + Amodiaquine and Arthemether + Lumefantrine. ${ }^{9}$ ACTs are cheap and effective treatment for malaria. ${ }^{6-8}$ However, they are more efficient when the patient receive the treatment within 24 to 48 hours after the onset of the first symptoms of the disease. ${ }^{6-}$ ${ }^{8}$ The objective of the National Programme Against Malarial in Cameroon is to ensure the most risky population for malaria infection to have access to effective antimalarial drugs. ${ }^{9}$ That is why considering the limited access to health services for some populations, ${ }^{9,10}$ the strategy for home management of malaria cases (HMMCs) at home was adopted in order to improve the accessibility of all to the rapid and effective treatment of malaria. ${ }^{9,10}$

According to WHO, Pharmacovigilance (PV) is the science and activities relating to the detection, assessment, understanding and prevention of adverse effects or any other possible drug-related problems. ${ }^{11}$ This activity is important and should be continued mostly because clinical trials prior to drugs marketing are conducted on limited number of participants in good health, thus not allowing to detect all potentials drug side effects that may cause unexpected illness, disability and even death in extreme cases. ${ }^{11}$ The implementation of HMMCs using ACTs in the health district of Mfou was a great opportunity to evaluate the safety of ACTs. Thus, this study aimed to determine the incidence of ADRs related to ACTs and to describe the riskiest groups according to the age and sex.
Correspondence: Bahina Essengue Louis, Catholic University of Central Africa, Yaoundé, Cameroon.

Tel.: +237.699536770

E-mail: bahinalouis@yahoo.fr

Key words: Artemisinin-based combination therapy, adverse reactions, malaria, children under 5, Mfou health district.

Acknowledgments: The authors gratefully acknowledge Mfou Health District Authorities. We extend our gratitude to the community health workers of all health areas in Mfou health district for their work in adverse drug reactions collection. Special thanks to the parents who volunteered accept the inclusion their children in the study.

Contributions: BEL conceived the study, participated in its design, data collection, analysis, interpretation and manuscript revision. YJC and SJ participated in the design of the study, coordination of data collection and manuscript revision. MBR participated in data interpretation and drafted the first manuscript. All authors read and approved the different study steps and the final manuscript.

Conflict of interests: The authors declare no potential conflict of interests.

Funding: none

Received for publication: 10 August 2017 Accepted for publication: 6 July 2018

This work is licensed under a Creative Commons Attribution NonCommercial 4.0 License (CC BY-NC 4.0).

(C) Copyright B.E. Louis et al., 2018

Licensee PAGEPress, Italy

Journal of Public Health in Africa 2018; 9:763 doi:10.4081/jphia.2018.763

\section{Materials and Methods}

\section{Study setting}

Mfou health district is located in the Center region of Cameroon at $25 \mathrm{~km}$ of Yaounde. The health district is a part of two departments (Mefou-Afamba, and NyongSo'o), and covers the sub-divisions of Mfou, Nkolafamba and Dzeng. The health district of Mfou is spread over $475 \mathrm{Km}^{2}$ with an estimated population of 65816 (unpublished data, 2013), in 12 health areas. Ewondo and Bene are the dominant population groups mostly Christians (catholic and protestan). Farmers represent a part of population while other people commute to the city of Yaounde daily for work or commerce. Malaria and respiratory infections are diseases most prevalent in the health district of Mfou, followed by sexually trans- 
mitted infections, including HIV/Aids which is the cause of $30 \%$ of hospital admissions (unpublished data, 2013).

\section{Study design}

This was a prospective, observational, cohort study of adverse events associated with ACTs, conducted from January 2013 to November 2013. The study was designed as cohort event monitoring system, ${ }^{12}$ of the HMMCs using ACTs implemented in Mfou health district.

\section{Study participants}

The study population consisted of children under 5 treated for malaria using ACTs at home.

\section{Sampling size and technique}

An exhaustive sampling method was applied for children under 5 treated at home with ACTs prescribed by community health workers during the study period.

\section{Data collection stools and methods}

An elaborated PV form was used for data collection and filled by trained community health workers involved in the HMMCs. All suspected ADRs following ACTs administration and other clinical events were recorded.

\section{Data analysis}

Data were entered into the computer using Epi Info version 3.5.3 and analysis was done using Statistical Package for Social Sciences (SPSS), statistical software version 20. Frequency tables and cross tabulations were generated and presented as tables. Categorical variables were presented as frequencies and proportions and association between two of them assessed using Chi square test. Level of significance was determined by a P-value of $<0.05$.

\section{Ethical considerations}

The study was approved by the Mfou Health District Authorities. Data collection was conducted confidentially and after obtaining parents' informed consent. Children experiencing adverse reactions after drugs administration were notified to Mfou Health Authority in order to receive appropriate care.

\section{Results}

\section{Socio-demographic characteristics of children}

As a whole, four hundred and seventynine (479) PV forms were filled. There were $56.8 \%(n=272 / 479)$ of males and $43.2 \%$
( $n=207 / 479$ ) of female children under 5 . The most represented age group was 25-59 months $(49.5 \% ; n=237 / 479)$. Table 1 shows the socio-demographic characteristics of treated children with ACTs.

\section{Incidence of adverse reactions in treated children}

Out of the total number of children that have been treated with ACTs, 27.1\%
( $n=130 / 479)$ had experienced one form of adverse reactions following drug administration, among them, $43.8 \%(\mathrm{n}=57 / 130)$ were females and $56.2 \%(n=73 / 130)$ were males. The main experienced ACTs reactions are shown by Figure 1. All ADRs were common side effects reported in the drug notice as associated to ACTs. Tiredness (43.1\%; $\mathrm{n}=56 / 130)$ was the most observed adverse reactions followed by lack of appetite

Table 1. Socio-demographic characteristics of children.

\begin{tabular}{lcc} 
Age groups (months) & Frequency & Proportion (\%) \\
$6-11$ & 70 & 14.6 \\
$12-24$ & 172 & 35.9 \\
\hline $25-59$ & 237 & 49.5 \\
Total & 479 & 100 \\
\hline
\end{tabular}

Table 2. Experienced adverse Artemisinin-based combination therapies reactions according to the age in months.

\begin{tabular}{|c|c|c|c|c|c|c|c|}
\hline & \multicolumn{2}{|c|}{$6-11$} & \multicolumn{2}{|c|}{$12-24$} & \multicolumn{2}{|c|}{$25-59$} & \multirow[t]{2}{*}{ Total, n } \\
\hline & n & $\%$ & n & $\%$ & n & $\%$ & \\
\hline Tiredness & 2 & 3.6 & 23 & 41.1 & 31 & 55.4 & 56 \\
\hline Lack of appetite & 3 & 9.4 & 12 & 37.5 & 17 & 53,1 & 32 \\
\hline Headache & 3 & 23.1 & 4 & 30.8 & 6 & 46.2 & 13 \\
\hline Vomiting & 2 & 13.3 & 4 & 26.7 & 9 & 60 & 15 \\
\hline Others & 2 & 14.3 & 9 & 64.3 & 3 & 21.4 & 14 \\
\hline Total & 12 & 9.2 & 52 & 40 & 66 & 50.8 & 130 \\
\hline
\end{tabular}

Table 3. Prevalence of adverse Artemisinin-based combination therapies reactions according to the sex of children.

\begin{tabular}{|c|c|c|c|c|c|}
\hline & & & & & Total, $\mathbf{n}$ \\
\hline & $\mathbf{n}$ & $\%$ & $\mathrm{n}$ & $\%$ & \\
\hline Tiredness & 24 & 42.9 & 32 & 57.1 & 56 \\
\hline Lack of appetite & 17 & 53.1 & 15 & 46.9 & 32 \\
\hline Headache & 6 & 46.2 & 7 & 53.8 & 13 \\
\hline Vomiting & 6 & 40 & 9 & 60 & 15 \\
\hline Others & 4 & 28.6 & 10 & 71.4 & 14 \\
\hline Total & 57 & 43.8 & 73 & 56.2 & 130 \\
\hline
\end{tabular}

Table 4. Occurrence of adverse Artemisinin-based combination therapies reactions according to age and sex.

\begin{tabular}{lccc} 
& \multicolumn{2}{c}{ Occurrence of adverse reactions } & P-value \\
Observed & Non-observed & \\
Age groups (months) & $\mathrm{n}(\%)$ & $\mathrm{n}(\%)$ & $>0.05$ \\
$6-11$ & $12(9.2)$ & $58(16.6)$ & \\
$12-24$ & $52(40)$ & $119(34.1)$ & \\
$25-59$ & $66(50.8)$ & $172(49.3)$ & $>0.05$ \\
Sex & & & \\
& & & \\
Male & $74(56.2)$ & $182(52.1)$ & \\
Female & $57(43.8)$ & $349(100)$ & \\
Total & $130(100)$ & & \\
\hline P< & &
\end{tabular}

$\mathrm{P}<0.05$ (significant) and $\mathrm{P}>0.05$ (non-significant). 
(24.6\%; $n=32 / 130)$. Tiredness was most reported among children aged 25-59 (55.4\%, $\mathrm{n}=31 / 130)$ and $12-24(41.1 \% ; \mathrm{n}=23 / 130)$, while children aged 6-11 months had most suffered from lack of appetite and headache $(25 \% ; n=3 / 12)$ (Table 2). According to the sex, both female $(42.1 \% ; n=24 / 57)$ and male $(56.2 \% ; n=32 / 73)$ children had most suffered from tiredness after ACTs administration (Table 3).

\section{Association between age, sex and the incidence of adverse ACTs reactions}

Table 4 summarizes the association between age, sex and the incidence of adverse ACTs reactions. Adverse reactions were most observed in children aged 25-59 months $(50.8 \% ; n=66 / 130)$ and male children $(56.2 \% ; n=74 / 130)$, but not significant association was found.

\section{Discussion}

Malaria remains one of the major public health concerns in Cameroon. ${ }^{10}$ In spite of enhanced control efforts, malaria is responsible for about $40-50 \%$ of hospital visits, $30 \%$ of hospital admissions, $40 \%$ of deaths among children under 5 and $35-40 \%$ of total deaths in health facilities. ${ }^{10}$ Malaria treatment is frequently initiated at home, most of time with street drugs. ${ }^{13}$ No informal used of ACTs for self-treatment of malaria was reported, indicating the effectiveness of the HMMCs strategy, thus the decrease of irrational use of the antimalarial drugs related problems. ${ }^{14,15}$ In the HMMCs

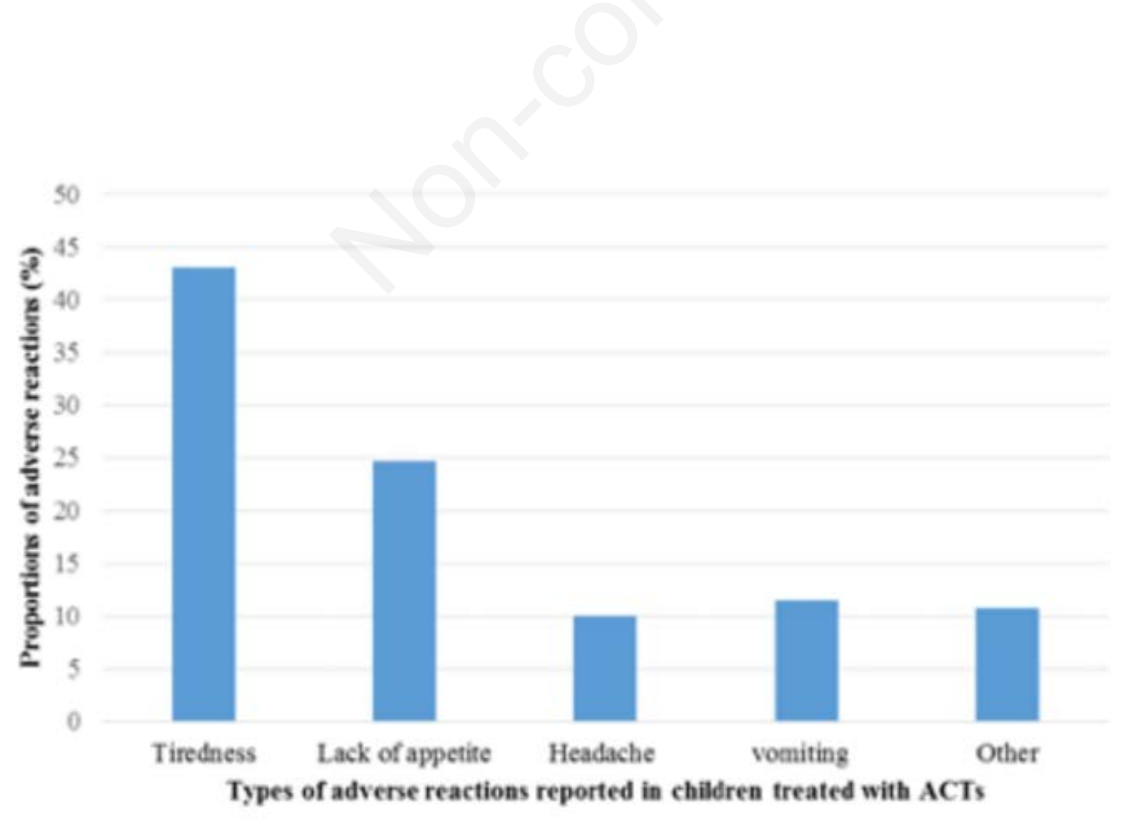

Figure 1 Distribution of reported adverse reactions in treated children with Artemisininbased combination therapies (other ADRs: nervousness, diarrhea, cough, insomnia, dizziness). Artemisinin derivatives were always used in combined form (bi-therapy). This should probably contribute to the decrease of drug resistance and hence the treatment effectiveness. ${ }^{16-18}$

ACTs induce side effects, but not systematically. ${ }^{19}$ In this study, common adverse ACTs reactions were reported, without life-threatening adverse reactions that could result in the end of treatment. All adverse events observed in children after ACTs administration were already known and listed in package inserts. ${ }^{19}$ This confirms the safety of ACTs and their tolerance. ${ }^{16,17}$ Contrary to studies from Nigeria, ${ }^{19}$ Kenya $^{20}$ and Zambia, ${ }^{21}$ itching, ear and eye disturbances and abdominal pain were not observed among the study population. Tiredness was the most reported adverse effects attributed to ACTs observed in treated children, followed by lack of appetite, vomiting and other side effects (nervousness, diarrhoea, cough, insomnia, dizziness). ${ }^{22}$ It was documented that adverse ACTs reactions as tiredness, lack of appetite, dizziness are mostly induced by amodiaquine component. ${ }^{23}$ This can partially explain why tiredness and lack of appetite were most observed considering that ACTs used in Cameroon include Artesunate + Amodiaquine. $^{9}$

Regarding the age and sex, children aged 12-24 months and male children had most experienced ACTs adverse reactions. Tiredness and vomiting were most reported among male children, while lack of appetite was mostly found in female children. strategy implemented in Cameroon,
However, no significant association was found between the incidence of adverse ACTs reactions and age and sex of children. This is similar to the findings of Adisa et al., (2008), in which sex did not appear to have any significant effects on the incidence ACTs adverse reactions. ${ }^{19}$

This study had some limitations. Although we worked with children patients receiving antimalarial drugs (ACTs) for treatment of malaria and ADRs collected by community health workers, we did not apply the world health organization assessment scale, ${ }^{24}$ to classify the adverse drug events as certain, probable, possible, unlikely, and unclassified. In addition, the fact that prescribers (community), were in charge of data collection could also induce some bias.

\section{Conclusions}

No informal use of ACTs for self-treatment of malaria was reported and Artemisinin derivatives were always used in combined form (bi-therapy). The prevalence of side effects of ACTs used as firstline therapy for treatment of uncomplicated malaria was found to be relatively low and tolerable. Tiredness was the most adverse reactions reported, age group 25-59 months and male children were most affected, but significant association was found between age, sex and incidence of ACTs adverse reactions. HMMCs using ACTs should be encouraged and effort should be made to continue to involve community health workers in the strategy. Community health workers should be trained in order to improve the recognizing and reporting of adverse effects.

\section{References}

1. World Health Organization. Partnership for malaria control: engaging the formal and informal private sectors Geneva: WHO/TDR; 2006.

2. Greenwood B. Anti-malarial drugs and the prevention of malaria in the population of malaria endemic areas. Malar J 2010:S2.

3. Organisation Mondiale de la Santé. Module de formation à la lutte contre le paludisme : prise en charge du paludisme. 2013. Organisation mondiale de la Santé, 20 avenue Appia, 1211, Genève.

4. Organisation mondiale de la Santé. Mise à l'échelle nationale de la prise en charge à domicile du paludisme. 2005 . Organisation mondiale de la Santé, 20 avenue Appia, 1211, Genève. 
5. ACT Consortium, London School of Hygiene \& Tropical Medicine. The REACT Facilitator and Participant Manuals on Improving Malaria Diagnosis and Treatment and on Improving the Quality of Care. 2010.

6. Antimalarial Drug Combination Therapy, Report of a WHO Technical Consultation. Geneva: WHO; 2001.

7. World Health Organization: World Malaria Day April 25th 2010. Available from: http:/www. who.int/malaria/en/

8. Mokuolu OA, Okoro EO, Ayetoro SO, Adewara AA. Effect of artemisininbased treatment policy on consumption pattern of antimalarials. Am J Trop Med Hyg 2007;76:7-11.

9. Republic of Cameroon, Ministry of Public Health. Plan Stratégique National de Lutte contre le Paludisme au Cameroun 2007-2010. 2006. Ministry of Public Health. Yaoundé.

10. Institut National de la Statistique INS/Cameroun and ICF International. Enquête Démographique et de Santé et à Indicateurs Multiples (EDS-MICS) 2011. Available from: http://dhsprogram.com/pubs/pdf/FR260/FR260.pdf.

11. World Health Organization: The importance of pharmacovigilance: safety monitoring of medicinal products. WHO, Geneva; 2002.

12. A Practical Handbook on the Pharmacovigilance of Antimalarial
Medicines. WHO 2007:9-30.

13. Deressa W, Ali A, Enqusellassie F. Selftreatment of malaria in rural communities Butajira southern Ethiopia. Bull WHO 2001;81:261-8.

14. Talisuna OA, Sarah G, D'Alessandro U. Pharmacovigilance of antimalarial treatment in Africa; Is it possible. Malaria J 2006;5:50.

15. Dorsey G, Njama D, Kamya MR, Rosenthal P. A longitudinal assessment of different first-line therapies for uncomplicated falciparum malaria in Kampala, Uganda. 50th Annual Meeting of the American Society of Tropical Medicine and Hygiene, Atlanta. 2001.

16. Lyda O, Iveth G, Piero O, Walt RJ. Artemisininbased combination therapy for uncomplicated Plasmodium falciparum malari.a in Colombia. Malaria $\mathrm{J}$ 2007;6:25.

17. Erah PO, Avienmughare G, Okhamafe OA. Plasmodium falciparum resistance to chloroquine in five communities in Southern Nigeria. Afr J Biotechnol 2003;2:384-9.

18. World Health Organization. The Importance of pharmacovgilance safety monitoring of Medicinal products. Geneva: WHO; 2002.

19. Adisa R, Fakeye TO, Dike D.Evaluation of adverse drug reactions to artemisinin-based combination thera- py in a Nigeria university community. Trop J Pharm Res 2008;7:937-44.

20. Nyamongo IK. Home case management of malaria: an ethnographic study of lay people's classification of drugs in Suneka division Kenya. Trop Med Int Health 1999;4:736-43.

21. Williams HA, Kachur SP, Nalwamba $\mathrm{NC}$, et al. A community perspective on the efficacy of malaria treatment options for children in Lundazi district, Zambia. Trop Med Int Health 1999;4:641-52.

22. Morgan D. Focus Groups as Qualitative Research. London: Sage; 1997.

23. Abdullah A, Moh'd O. Pharmacovigilance in Zanzibar; Current status. Pharmacovigilance Unit-Zanzibar National Malaria Control Programme. The Newsletter for the East African Network for monitoring antimalarial treatment (EANMAT). 2005;8.

24. Central Drug Standard Control Organization. Directorate General of Health Services, Ministry of Health and Family Welfare, Govt. of India; Protocol for National Pharmacovigilance Programme Version 1. 2004. Available from: http://www. nlsenlaw.org/wp-content/uploads/ 2013/08/National-PharmacovigilanceProtocol.pdf 